\title{
Rainfall-Altitude Relationship in Saudi Arabia
}

\author{
Khalid Al-Ahmadi ${ }^{1}$ and Sharaf Al-Ahmadi ${ }^{2}$ \\ ${ }^{1}$ King Abdulaziz City for Science and Technology, P.O. Box 6086, Riyadh 11442, Saudi Arabia \\ ${ }^{2}$ Taibah University, P.O. Box 344, Madinah 30001, Saudi Arabia \\ Correspondence should be addressed to Khalid Al-Ahmadi; alahmadi@kacst.edu.sa
}

Received 24 December 2012; Revised 23 February 2013; Accepted 26 February 2013

Academic Editor: Harry D. Kambezidis

Copyright (C) $2013 \mathrm{~K}$. Al-Ahmadi and S. Al-Ahmadi. This is an open access article distributed under the Creative Commons Attribution License, which permits unrestricted use, distribution, and reproduction in any medium, provided the original work is properly cited.

\begin{abstract}
Relations between rainfall and the altitude of the terrain can have significant implications for rainfall-runoff studies in hydrology. The aim of this paper is to report on a study of relationships between annual and seasonal rainfall and the altitude of the terrain in Saudi Arabia (SA) using global ordinary least square (OLS) and local geographically weighted regression (GWR) methods. Results using the OLS method showed a significant correlation between altitude and spring rainfall, with a coefficient of determination of $r^{2}=0.54, P<.05$ but no significant correlation for the annual and other seasons' rainfalls. The relationships were more pronounced when GWR local analysis was performed with coefficients of determination of $r^{2}=0.78,0.64,0.83,0.82$, and 0.71 for annual, winter, spring, summer, and fall rainfalls, respectively. There was some variation in the parameter estimates derived with GWR, but the majority of the estimates indicated a positive association. Results from this study corroborate those of selected other studies in which rainfall and altitude were found to be correlated spatially. The authors concluded that the use of a nonstationary local model such as GWR enabled them to provide a deeper explanation of relations between rainfall and the altitude of the terrain than a global model such as OLS in terms of spatial estimation and prediction.
\end{abstract}

\section{Introduction}

Understanding, estimating, and predicting spatial patterns and amounts of rainfall are potentially important for a diversity of human, social, economic, hydrological, and ecological activities such as agricultural planning, water resources management, flood prevention, groundwater recharge, forest management, industry, and the welfare of the human population and the national economy [1-3]. The spatial and seasonal patterns and total amounts of rainfall are key factors in the water balance equation of Saudi Arabia [4].

Many scientists have studied associations between the spatial and temporal distributions of rainfall and topographic factors such as altitude [5-11], geographic location [8, 9], slope $[5,7-10]$, aspect $[5,7,10,11]$, proximity to moisture sources such as seas, oceans or lakes $[6,7]$ and exposure $[5,7$, 8]. These topographic features have been applied as factors to explore the relationships between topography and the spatial distribution of mean annual, seasonal, and monthly rainfall totals in different parts of the world using univariate and multiple regression models and geostatistical methods.
These studies found that the spatial variability of mean annual and mean monthly rainfall are best captured by such topographic variables but results indicated that there were varying degrees of success. For example, Sevruk et al. [8] considered altitude as the best overall predictor of rainfall distribution. Basist and Bell [5] found that exposure and the product of elevation and exposure variables were related to spatial variability of annual and mean rain falls, while elevation and slope were the weakest predictors. Konrad [7] found that altitude was strongly correlated with light rainfall events but exposure and proximity to water sources were associated with heavy rainfall events. Al-Ahmadi et al. [12] explored the spatial variations between topography and mean annual and seasonal rainfalls in the south-west of Saudi Arabia using Kruskal-Wallis One-Way Analysis of Variance (ANOVA). The topographic factors included physiographic features (topography), altitude, slope, proximity to a ridge or crest of mountains, and proximity to the Red Sea. When these factors were processed, the results showed that they were statistically significant for estimating annual and seasonal rainfalls. 
Rainfall distribution often differs on the windward and leeward sides of mountain ranges. In Saudi Arabia, the amount of rainfall on the western or windward slopes of the Asir Mountain Escarpment decreases in a northerly direction due to the prevalence of winter monsoonal cloud formation. The eastern or leeward slopes of the Mountains have lower rainfall than the western side, due to the Asir Mountains blocking the westerly and north westerly winds carrying moisture from nearby water bodies [13]. Hayward and Clarke [6] analyzed the association between rainfall, altitude, and distance from the sea using multiple regression analysis. Their results showed differences between ocean-facing and rainshadow stations. The associations between monthly rainfall and altitude were more pronounced for rain-shadow stations than for ocean-facing stations. Also, rainfall in the monsoonal months increased with altitude and decreased with proximity to the sea. Hatzianastassiou et al. [14] investigated the spatial and temporal distribution of precipitation in Greece and reported a difference between the wetter western (windward) and the drier eastern Greece (leeward), whereas there was very little precipitation over the Greek islands, chiefly in the southern parts of Greece.

This study focused solely on the altitude factor as it was the major factor and there was considerable complexity in applying all of the known factors in a study of the huge geographical area of Saudi Arabia. There is a well-known physical relationship between altitude and rainfall $[15,16]$, which has been studied by many scientists working in different parts of the world $[3,5,10,11,17-23]$. Several authors have found, however, that using the mean altitude of the terrain within a circle centered on the location of the rain-gauge station and with a radius of a few kilometers improves the fit of the relation more than using the altitude of the station itself $[7,24$, 25]. Pedgley [26] found that precipitation in the midlatitudes is associated most strongly with smooth topography near the rain-gauge. Chaun and Lockwood [24] used the mean altitude of the rain-gauge within an $8 \mathrm{~km}$ radius about the metrological station. Hill et al. [25] considered the average altitude of $4 \mathrm{~km}$ grid squares. Konrad [7] adopted the mean elevation within a $10 \times 10 \mathrm{~km}^{2}$ grid. Johansson and Chen [27] resampled elevations taken from $50 \times 50 \mathrm{~m}^{2}$ into a window of a $4 \times 4 \mathrm{~km}^{2}$ grid. Gouvas and Sakellariou [28] found that the variable taking into account the surrounding altitude of the adjacent mountains improved the description of the increased rainfall in mountainous areas when compared to using the altitude of the station itself. Alijani [11] calculated the mean altitude of the terrain within a circle with a radius of $2.5 \mathrm{~km}$ about a recording station. More recently, Gouvas et al. [3] suggested that the variable $Z^{\prime}$, which takes into account the altitude within a radius of $2.5 \mathrm{~km}$ around the recording station, improved the predictive performance of the model and can be used in the interpolation procedure.

Classical global modeling techniques, such as ordinary least squares (OLS) linear regression or spatial regression methods, assume a rendering process which is regarded as being stationary, that is, spatially invariant or homogeneous. This presupposes that the process runs similarly over the entire area of study, and that there are no local variations in the associations between the dependent and explanatory variables [29]. Thus a single set of global parameters is used to describe the process. Applying such techniques may, however, obscure regional variations in the associations between predictors and the outcome variable. The OLS method addresses neither the issue of the nonstationarity nor the occurrence of spatial autocorrelation among residuals [30], yet it is progressively apparent that local variations between the independent and dependent variables can play significant exploratory and explanatory roles in the analysis of spatial data [29]. Geographically weighted regression (GWR) is a local spatial statistical technique used to analyze spatial nonstationarity, where the relationships between the variables can differ from location to location [31]. Maps generated from the application of such analyses can play a key role in exploring and interpreting spatial nonstationarity [32].

Rainfall exhibits nonstationary processes, as it differs in type, frequency, and amount from one location to another. This feature of spatial phenomena might be stated as regional variation or spatial drift. Thus, the rainfall-altitude association can be considered as a nonstationary relationship. While there does not appear to have been many scientific studies reported in the literature on the use of GWR to assess rainfallaltitude relationships, Brunsdon et al. [33] used GWR to explore the association between rainfall and altitude in Great Britain. They studied the relationship between annual rainfall totals and rain-gauge elevations over Great Britain and found that such analysis allowed the spatial drift of regression parameters to be identified, estimated, and mapped. Lloyd [34] used nonstationary models, namely, moving window regression (MWR), and GWR to explore the spatial variation concerning the relation between altitude and monthly rainfall amounts in the United Kingdom and concluded that global models masked widespread local variation and that local models increased prediction accuracy. Lloyd [34] also concluded that the association between elevation and rainfall is complex, as are spatial variations of rainfalls and methods such as GWR and MWR offer a great opportunity to explore and understand these variations.

The present study aims to explore and understand the spatial variation in the relationship between mean annual and mean seasonal rainfalls and the altitude of rain-gauge stations in Saudi Arabia using global OLS and local GWR models with monthly rainfall data over the years from 1971 to 2005 .

\section{Materials and Methods}

2.1. Study Area. Saudi Arabia lies between $15^{\circ}$ and $30^{\circ}$ north of the equator and between $37^{\circ}$ and $52^{\circ}$ east of the Greenwich meridian (Figure 1). It is surrounded by the Red Sea $(2250 \mathrm{~km})$ to the west and the Arabian Gulf $(500 \mathrm{~km})$ to the east, which are considered as the main sources of water vapour in Saudi Arabia. The topography of the country can be divided into regions of coastal plains, the Western Heights, the Western plateau, the Najd plateau, the Eastern plateau, the Northern plateau, and the Empty Quarter desert (Figure 2). The coastal plains include the Tihama coast to the west of the western mountains, which is about $1800 \mathrm{~km}$ long, and the eastern coastal plain on the Arabian Gulf, which is some 
$500 \mathrm{~km}$ long. The Western Heights has one of the notable topographic features of Saudi Arabia, which is called the Hijaz-Asir Scarp. It extends parallel to the western coastal plains for some $1700 \mathrm{~km}$ and the elevation rises to $2990 \mathrm{~m}$. Its width ranges from $120 \mathrm{~km}$ to $200 \mathrm{~km}$, narrower at the north and wider in the center and south. The slope of the mountains is relatively steep towards the sea in the west but less steep towards the east. The Najd plateau at the center of Saudi Arabia rises to between 800 and $1100 \mathrm{~m}$ and includes the Tuwayq Mountains, which form a range spanning $800 \mathrm{~km}$. The elevation of the Eastern plateau ranges between $170 \mathrm{~m}$ and $400 \mathrm{~m}$ [35].

2.2. Rainfall and Altitude Data. This study used data from 180 rainfall stations with 35 years of monthly records from 1971 to 2005 . The data were supplied by the Hydrology Department of the Ministry of Water and Electricity. The monthly rainfall data were categorized into four seasons, namely, winter (December-February), spring (March-May), summer (June-August), and fall (September-November). From the monthly rainfall data, the authors calculated the means of the annual and seasonal rainfalls. The altitude data was derived from an ASTER DEM with 30 meters spatial resolution [36].

2.3. Geographically Weighted Regression (GWR). Ordinary least squares (OLS) or linear least squares is a global method for estimating the association between a dependent variable and a set of one or more independent variables and can be written as [37]

$$
y_{i}=\beta_{O}+\sum_{k} \beta_{k} x_{i k}+\varepsilon_{i}
$$

GWR extends the conventional OLS regression structure by permitting local rather than global parameters to be identified and estimated so that the model is rewritten as [31]

$$
y_{i}=\beta_{O}\left(u_{i}, v_{i}\right)+\sum_{k} \beta_{k}\left(u_{i}, v_{i}\right) x_{i k}+\varepsilon_{i}
$$

where the dependent variable $y$ is regressed on a set of independent variables, each denoted by $x_{k}$ and the parameters are allowed to vary over space. Herein, $\left(u_{i}, v_{i}\right)$ denotes the longitude and latitude coordinates of the $i$ th point in space and $\beta_{k}\left(u_{i}, v_{i}\right)$ is a realization of the continuous surface of parameter values and measurements of this surface taken at a set of points to denote the spatial variability of the surface $[31,38]$.

GWR is a local spatial statistical method used to examine and determine the spatial nonstationarity, when the relationships among variables vary from location to location [31]. The spatial influences among neighborhoods can be assessed by applying GWR; however, this cannot be assessed using a conventional OLS approach, which only produces a single regression equation to summarize global associations among the dependent and explanatory variables $[31,39]$. The GWR produces spatial data that explain the spatial variation in the associations among variables. The hypothesis is that features (observations) adjacent to one another have a greater effect on one another's parameter estimates than features farther apart [32]. In order to specify the geographical weighting structure in the GWR model, this requires the specification of a kernel shape and a bandwidth. Overall, if the observations are regularly distributed in the study area, then a kernel with a fixed bandwidth is an appropriate choice. If the observations are clustered and not regularly spaced, then kernel with an adaptive bandwidth can be selected. The bandwidth can be specified using three methods: user-supplied, minimizing the cross-validation function, or minimizing the Akaike Information Criterion (AIC). The goodness of fit that has been used broadly in GWR is the corrected AIC [37]. The AIC criterion in GWR is computed as [40]

$$
\mathrm{AIC}_{c}=2 n \log _{e}(\widehat{\sigma})+n \log _{e}(2 \pi)+n\left\{\frac{n+\operatorname{tr}(S)}{n-2-\operatorname{tr}(S)}\right\},
$$

where $n$ is the number of observations in the dataset, $\widehat{\sigma}$ is the estimate of the standard deviation of the residuals, and $\operatorname{tr}(S)$ is the trace of the hat matrix. The AIC can be used to compare models of the same independent variable and can also be used to compare the global OLS model with a local GWR model [37]. The coefficient of determination $\left(r^{2}\right)$ and the AIC are used in this study to compare the goodness of fit for the OLS and GWR models.

GWR models will be used to build a local regression equation for each rainfall station in the study area in order to examine the relationship between rainfall and altitude. Wheeler [41] noted, however, that when the coefficient estimates for the altitude variable correlate locally and across space, there may be problems with local collinearity, which can be assessed for predictor variables by computing the condition number [42]. The condition number is a diagnostic of how sensitive a linear equation solution is to small changes in matrix coefficients. Results associated with condition numbers larger than 30 may be unreliable and be a sign of collinearity problems [43]. Another issue in the GWR model is that over- and underpredictions for a well specified regression model should be randomly distributed. Clustering of over- and/or underpredictions is evidence that at least one key explanatory variable is missing. The spatial autocorrelation (Moran's I) method can be used to examine whether or not the GWR model residuals exhibit statistically significant spatial clustering. The Global Moran's I statistic provides a measure of the degree of spatial autocorrelation based on both the locations of events and the values associated with the events at the same time. It indicates the degree of spatial concentration or dispersion for a given point pattern [44]. The index, $I$, is calculated as follows:

$$
I=\frac{n}{S_{O}} \frac{\sum_{i=1}^{n} \sum_{j=1}^{n} \omega_{i, j} Z_{i} Z_{j}}{\sum_{i=1}^{n} Z_{i}^{2}}
$$

where $Z_{i}$ is the deviation of an attribute for feature $I$ from its mean $\left(x_{i}-\bar{X}\right) ; \omega_{i, j}$ is the spatial weight between feature $i$ and $j ; n$ is equal to the total number of features; finally, $S_{O}$ is the aggregate of all the spatial weights. Statistically significant clustering of high and/or low residuals (model 


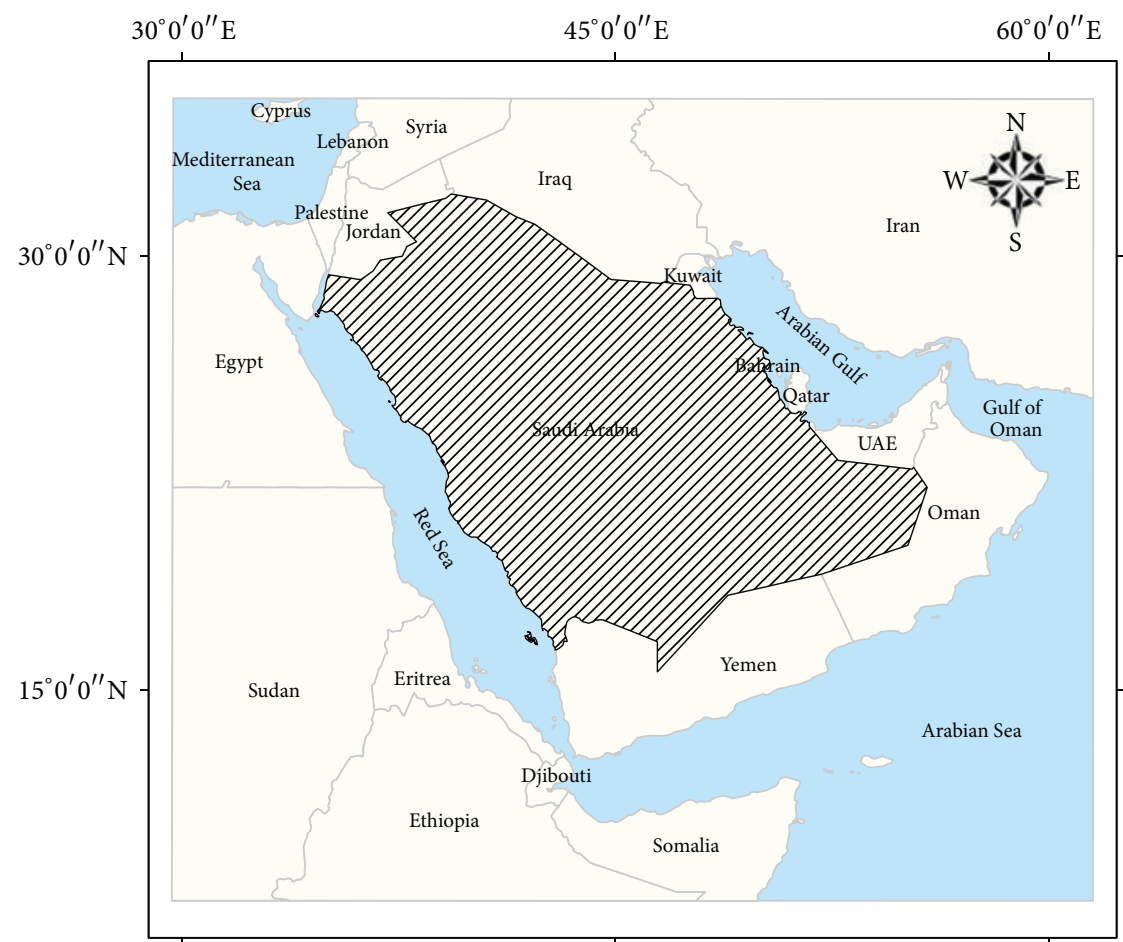

ZZ Study area

Countries boundaries

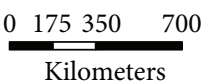

Figure 1: Study area.

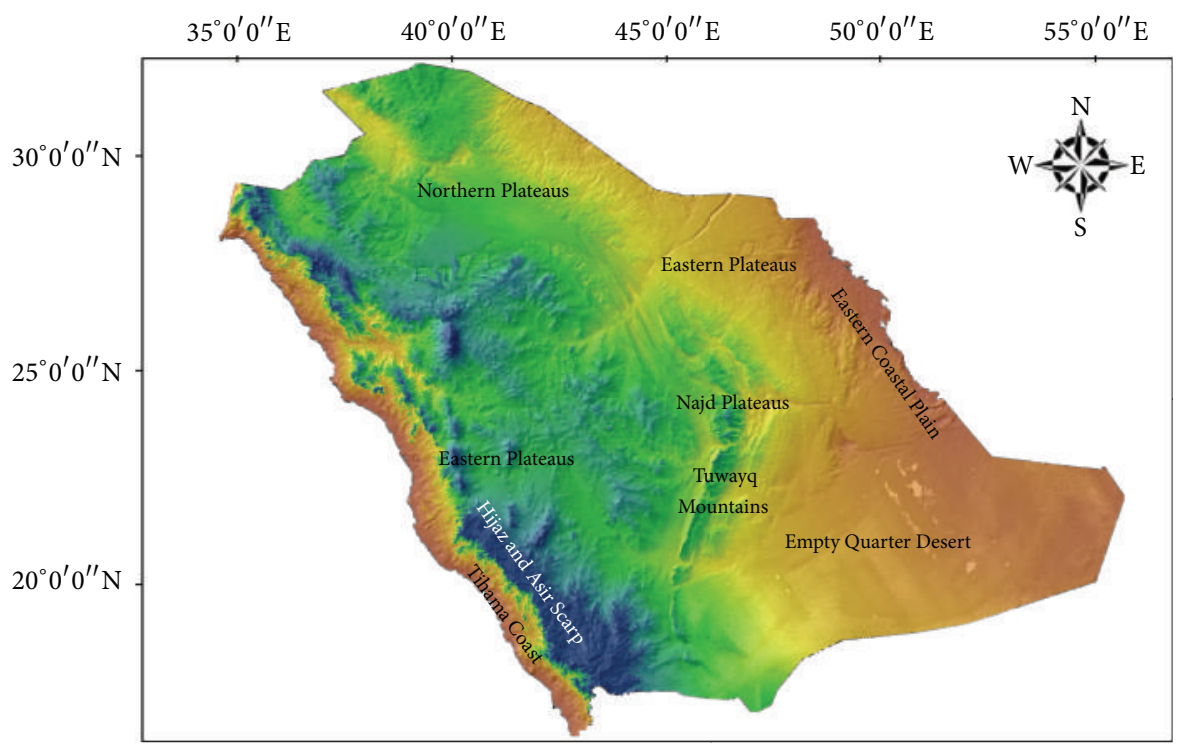

High: 2990 m

Low: 0

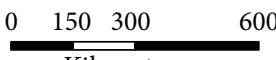

Kilometers

FIgUre 2: Digital elevation model of Saudi Arabia. 
under- and overpredictions) indicates that the GWR model is misclassified [45].

2.4. Climate and Rainfall in Saudi Arabia. According to Koppen-Geiger climatic types, Saudi Arabia is classified as hot, dry desert climate coded as BWh, where "B" indicates that the land area is arid, " $\mathrm{W}$ " indicates desert precipitation falling mainly in the winter season, and " $\mathrm{h}$ " indicates a hot, dry climate [46], with the exception of the southwestern highlands. Most of Saudi Arabia falls under the dominant influence of the subtropical high-pressure system causing significant variation in temperature and humidity. The climate is affected by the various air mass movements, local topography, and proximity to moisture sources. The topography has a distinct influence on temperature and rainfall. The Asir Mountains in the southwestern region exhibit moderate temperatures and high average annual rainfall, while average annual rainfall is very low for the rest of the country and irregular. The temperature is high and humidity is low, with the exception of small strips of coastal areas [47, 48].

The climate of Saudi Arabia can be explained by considering the different air mass movements, which influence the rainfall distribution [49]. There are three major fronts of moisture flowing into the Kingdom, including

(i) maritime tropical air masses (monsoon type), which originate from the Indian Ocean and the Arabian Sea, bringing warm and moist air, which produces large amounts of rainfall in the south, southwest, and southeast. This front prevails during late fall and summer;

(ii) continental tropical air masses from the Atlantic Ocean through the middle and north of the African continent, which bring warm and moist air to the western coast and prevail in the winter season producing moderate to low amounts of rainfall;

(iii) maritime polar air masses, which originate from the eastern Mediterranean Sea and affect the north and northwest area of Saudi Arabia. They prevail in the winter season and produce high to moderate amounts of rainfall [48-51].

Average annual rainfall in Saudi Arabia is generally low and falls chiefly during winter and spring, except in the southwestern region, where the average annual rainfall is relatively high and occurs throughout the year due to the monsoonal conditions during summer and the north westerly Mediterranean air masses during winter [35]. In Saudi Arabia, rainfall during spring contributes the largest amount of total annual rainfall (37.11\%), followed by winter (23.14\%) and fall (22.21\%), while the lowest contribution is during summer (17.27\%). The maximum mean annual rainfall occurs during fall $(212 \mathrm{~mm})$ and summer $(208 \mathrm{~mm})$, followed by spring $(180 \mathrm{~mm})$ and winter $(113 \mathrm{~mm})$.

Figure 4 shows the mean annual and seasonal rainfall distribution in Saudi Arabia between 1971 and 2005. During the winter period, rainfall is influenced chiefly by the cyclonic system and the highest rainfalls $(43-113 \mathrm{~mm})$ occur in the southwest and northeast. The former can be attributed to the maritime polar air mass from the Mediterranean Sea and Atlantic Ocean, which is combined with local effects of the Red Sea and the Hijaz-Asir Escarpment, where orographic rainfall occurs, while the latter can be attributed to fronts from the Mediterranean, which bring moist and cool air masses to produce convective rainfalls [52]. Moderate rainfall (26-42 $\mathrm{mm}$ ) occurs in the central part and low rainfall in the north and the central south $(0-25 \mathrm{~mm})$. During spring, the highest rainfall $(71-180 \mathrm{~mm}$ ) occurs in the southwest, due to the effect of the monsoonal moist air penetration from the Indian Ocean. This region is also affected largely by the escarpment of the Asir Mountains. There is moderate rainfall $(39-70 \mathrm{~mm})$ in the central part, while the west, north, and east regions receive the lowest rainfall $(0-38 \mathrm{~mm})$ due to the dry northern air masses. During summer, the highest rainfall $(45-208 \mathrm{~mm})$ occurs in the southwest, which is a result of the convectional instabilities in the air. The moisture continues to be supplied from the southwesterly flow of monsoonal air, which produces thunder-storms in the south and along the Red Sea escarpment [4]. During fall, high and moderate rainfall (45-208 $\mathrm{mm}$ and $33-56 \mathrm{~mm}$ ) occurs in the southwest region and in the south part of the west region, while low rainfall (14-32 $\mathrm{mm}$ ) occurs in the west and in parts of the central and eastern regions. The lowest rainfall (0$13 \mathrm{~mm}$ ) is in the north, central-south, and on the east (lee ward) side of the Asir Mountains. During this season, the southwesterly air flow diminishes and the westerly air from the Mediterranean brings air moisture, which gives way to tropical winter conditions. The southern area comes under the influence of a combination of the Red Sea trough and the Mediterranean depression, causing rainfall [53].

\section{Results and Discussion}

This study set out to explore and understand the spatial variation in the relations between altitude and annual and seasonal rainfalls in Saudi Arabia using global OLS and local GWR models. The analyses were performed using ESRI ArcGIS software (v10.1). In the GWR model, the adaptive kernel with AIC estimated bandwidth was selected; that is, the bandwidth was found by minimizing the AIC value. The adaptive kernel rather than the fixed kernel was selected because the rainfall stations are not regularly positioned in the study area; that is, they are inhomogeneous and clustered in some areas.

As mentioned earlier, several scientific studies reported in the literature have shown that smoothed altitude values of rainfall stations (i.e., mean altitude around the station) can produce much better results than the absolute altitude at the rainfall station site itself. Firstly, OLS and GWR analyses were performed using different smoothing window sizes for annual and seasonal rainfalls to assess the performance through the coefficient of determination $\left(r^{2}\right)$. In order to assess the influence of the smoothing window size on the relationship between altitude and rainfall and to decide on the most appropriate window size, six spatial smoothing window sizes were tested against the annual and seasonal rainfalls. The mean altitude of rainfall stations was computed 


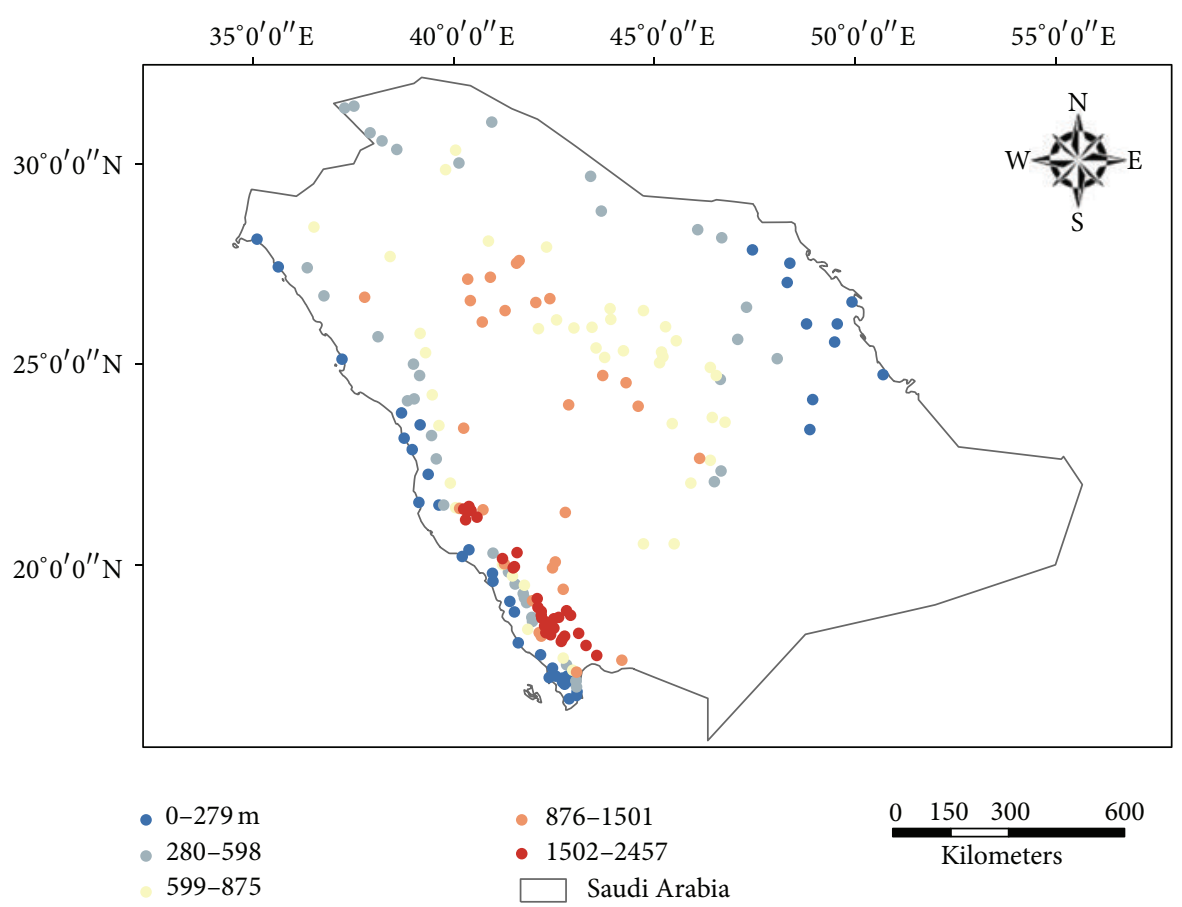

FIGURE 3: Rainfall stations with corresponding altitude.

within six square windows ranging in dimension from $1 \times$ 1 to $5 \times 5,10 \times 10,15 \times 15,20 \times 20$, and $25 \times 25 \mathrm{~km}^{2}$ as well as the source ASTER DEM data at $30 \times 30 \mathrm{~m}^{2}$ resolution.

Figure 5 shows the global coefficient of determination $\left(r^{2}\right)$ derived with OLS models against different smoothing window sizes of mean altitude values. Generally, the global OLS model explained about $50 \%$ of the variation for spring rainfall, while for annual, winter, summer, and fall, the model's explanations of the rainfall variations are less than $10 \%$. This might be attributed to the fact that the largest proportion of annual rainfall (37.11\%) occurred during spring and the highest rainfall totals $(71-180 \mathrm{~mm})$ during this season occurred in the south-west region of the area of study, where rainfall is affected largely by the escarpment of the Asir Mountains and the effect of the monsoonal moist air penetration from the Indian Ocean. Orographic rainfall occurs regularly in the Asir Mountains, while convective rainfall usually occurs in the foothills of these highlands. Although both orographic and convective rainfalls occur, after the influence by altitude, the former are affected to a much greater degree than the latter.

In terms of window sizes, the spring rainfall is highly related to altitude using $1 \mathrm{~km}$ windows $\left(r^{2}=0.55, P<0.05\right)$ followed by $30 \mathrm{~m}, 5 \mathrm{~km}$, and $10 \mathrm{~km}\left(r^{2}=0.54, P<0.05\right)$, while $20 \mathrm{~km}$ and $25 \mathrm{~km}$ windows showed the lowest relation $\left(r^{2}=0.34\right.$ and $\left.36, P<0.05\right)$. The average $r^{2}$ for annual and seasonal OLS models for each window size are 0.14 for $30 \mathrm{~m}$, $1 \mathrm{~km}, 5 \mathrm{~km}$, and $10 \mathrm{~km}, 0.13$ for $15 \mathrm{~km}, 0.11$ for $20 \mathrm{~km}$, and 0.09 for $25 \mathrm{~km}$.
Figure 6 shows the local coefficient of determination $\left(r^{2}\right)$ derived with GWR models against different smoothing window sizes of mean altitude values. Note that the annual and seasonal rainfalls were spatially associated with altitude by using the seven smoothing windows with $r^{2}$ ranging between 0.59 and 0.85 . The average $r^{2}=0.74$ using $30 \mathrm{~m}$ and $1 \mathrm{~km}, r^{2}=0.75$ using $5 \mathrm{~km}$ and $10 \mathrm{~km}, r^{2}=0.76$ using $15 \mathrm{~km}$ and $20 \mathrm{~km}$, and $r^{2}=0.73$ using $25 \mathrm{~km}$ window size. As the average of the coefficient of determination $\left(r^{2}\right)$ was low (0.09-0.14) using OLS and high (0.59-0.85) using GWR, the mean altitude window size was selected based on the GWR results. The selected window size in this study will be $15 \mathrm{~km}$, as it produced the highest value of $r^{2}$ value using the GWR model.

Comparisons of the coefficients of determination $\left(r^{2}\right)$ and AIC for both global OLS and local GWR models using the selected window size, $15 \mathrm{~km}$, are shown in Table 1 and Figure 7. The OLS models explained $11 \%, 4 \%, 54 \%, 1 \%$, and $-0.01 \%$ of the spatial variation of the annual, winter, spring, summer, and fall rainfalls, respectively. The only acceptable fit was during spring (54\%). The GWR models explained $78 \%, 64 \%, 83 \%, 82 \%$, and $71 \%$ of the spatial variation for the annual, winter, spring, summer, and fall rainfalls, respectively. As suggested by Burnham and Anderson [54], the difference of AICs between two models is considered significant if it is greater than 6 . The difference in the AICs between the OLS and GWR models ranged between 82 and 212 and showed strong evidence of an improvement in the fit of the model to the data for the GWR. The result implies that the GWR 


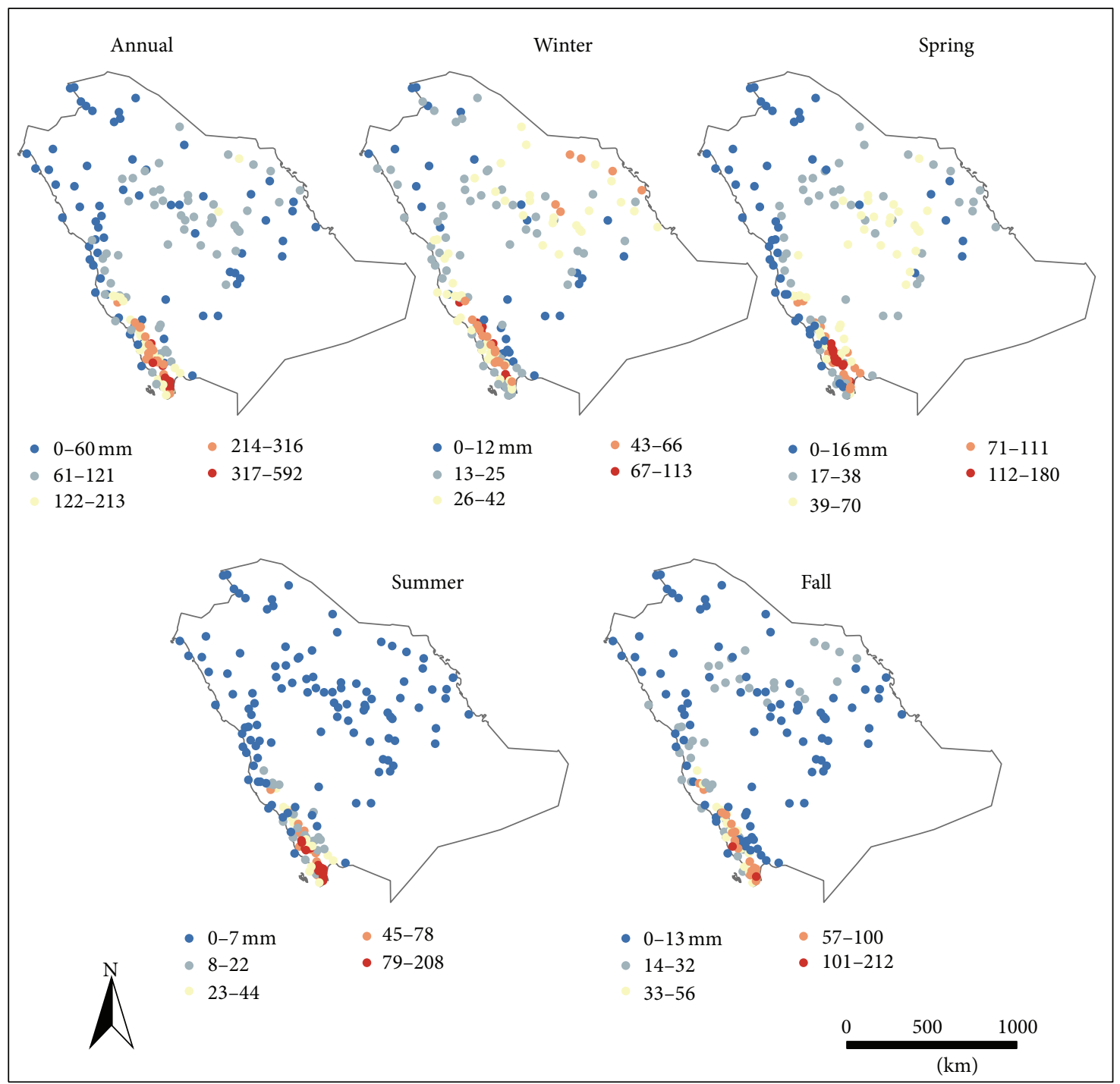

FIgURE 4: Mean annual and seasonal rainfall distribution in Saudi Arabia (1971-2005).

models explained much more of the variations in the relation between altitude and rainfall than did the OLS models. The OLS models failed to account for most of the spatial variation of rainfall during all seasons except spring, as the $r^{2}$ and AICs values show, so the GWR model was used to fit the model and the results are presented and discussed below.

The results were comparable to those found by $[33,34,55]$. For example, Lloyd [55] found that using monthly precipitation of Great Britain in 1999, the relationship between elevation and precipitation using the OLS seemed to be weakly related $\left(r^{2}=0.110\right)$, while the relationship improved using GWR $\left(r^{2}=0.599\right)$. In a different field of research, Mandal et al. [56] found that the relationship between breast cancer in females and prostate cancer in males at the county level in the United States was more pronounced when they performed GWR analysis $\left(r^{2}=0.552\right)$ compared to OLS $\left(r^{2}=0.332\right)$. Lin and Wen [57] examined the relationship between dengue-mosquito and dengue-human relationships
TABLE 1: Coefficient of determination $\left(r^{2}\right)$ and AICs derived by OLS and GWR models.

\begin{tabular}{lcccccc}
\hline Seasons & $\begin{array}{c}\text { OLS } \\
\left(r^{2}\right)\end{array}$ & $\begin{array}{c}\text { GWR } \\
\left(r^{2}\right)\end{array}$ & $\Delta\left(r^{2}\right)$ & $\begin{array}{c}\text { AIC for } \\
\text { OLS }\end{array}$ & $\begin{array}{c}\text { AIC for } \\
\text { GWR }\end{array}$ & $\Delta$ AIC \\
\hline Annual & $0.11^{*}$ & 0.78 & -0.67 & 2165 & 2007 & $158^{* *}$ \\
Winter & $0.04^{*}$ & 0.64 & -0.60 & 1581 & 1499 & $82^{* *}$ \\
Spring & $0.54^{*}$ & 0.83 & -0.29 & 1687 & 1589 & $98^{* *}$ \\
Summer & $0.01^{*}$ & 0.82 & -0.81 & 1803 & 1591 & $212^{* *}$ \\
Fall & -0.001 & 0.71 & -0.70 & 1784 & 1658 & $126^{* *}$ \\
\hline
\end{tabular}

* Significance level at level $P<0.05$.

${ }^{* *}$ Significant Difference where $\triangle$ AIC greater than 6.

and found that GWR (adjusted $r^{2}=0.59$ ) detected the geographical heterogeneity much better than OLS (adjusted $\left.r^{2}=0.04\right)$. Potential reasons as to why GWR performed much better than global OLS in this study could be attributed to 
TABLE 2: Coefficient of determination $\left(r^{2}\right)$ derived by GWR, percentage of over- and under estimated rainfall stations and percentage of rainfall stations with positive parameter estimate.

\begin{tabular}{lcccc}
\hline Seasons & GWR $\left(r^{2}\right)$ & $\begin{array}{c}\text { No. of overestimated } \\
\text { stations/total (\%) }\end{array}$ & $\begin{array}{c}\text { No. of underestimated } \\
\text { stations/total (\%) }\end{array}$ & $\begin{array}{c}\text { No. of stations with positive } \\
\text { parameter estimate/total (\%) }\end{array}$ \\
\hline Annual & $0.78^{*, * *}$ & $2 / 180(1.11 \%)$ & $4 / 180(2.22 \%)$ & $153 / 180(85 \%)$ \\
Winter & $0.64^{*, * *}$ & $3 / 180(1.66 \%)$ & $3 / 180(1.66 \%)$ & $114 / 180(63 \%)$ \\
Spring & $0.83^{*, * *}$ & $2 / 180(1.11 \%)$ & $4 / 180(2.22 \%)$ & $166 / 180(92 \%)$ \\
Summer & $0.82^{*, * *}$ & $3 / 180(1.66 \%)$ & $4 / 180(2.22 \%)$ & $139 / 180(77 \%)$ \\
Fall & $0.71^{*, * *}$ & $4 / 180(2.22 \%)$ & $3 / 180(1.66 \%)$ & $125 / 180(69 \%)$ \\
\hline
\end{tabular}

${ }^{*}$ Random standardized residuals $(-1.96<z$-score $<1.96),{ }^{* *}$ Condition number $<30$.

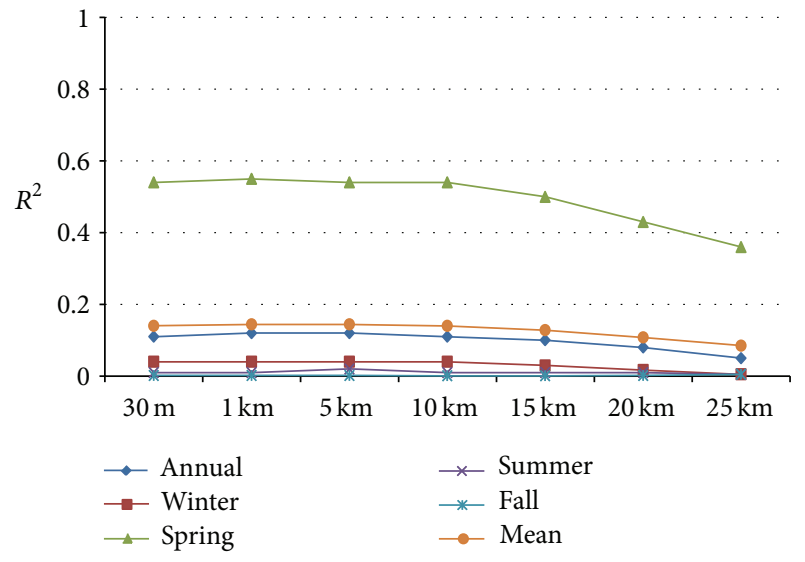

FIGURE 5: Coefficient of determination $\left(r^{2}\right)$ derived by OLS model against different smoothing window size of mean altitude values.

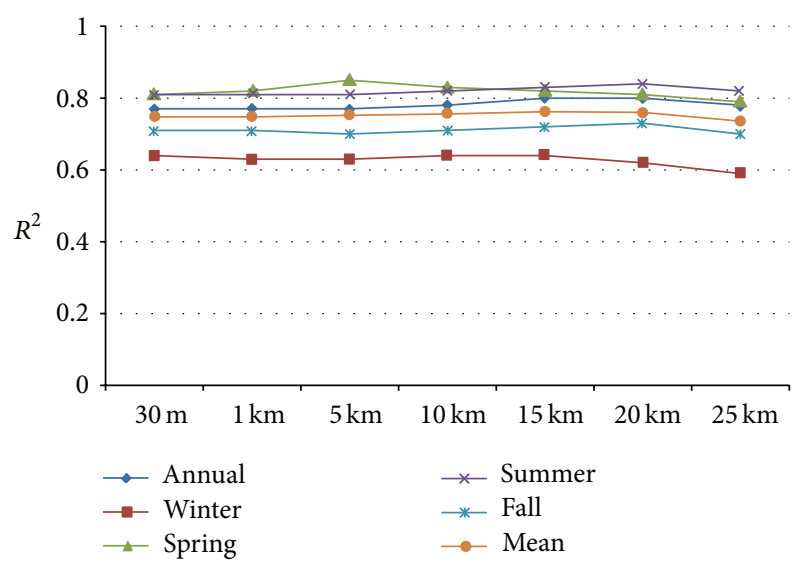

FIGURE 6: Coefficient of determination $\left(r^{2}\right)$ derived by GWR model against different smoothing window size of mean altitude values.

the former model distinguishing spatial variation in the relationships between altitude and rainfall while the latter global model masked such variations. Also, as the observed spatial and temporal distributions of rainfall are nonstationary; that is, they vary from one location to another; the global OLS model would probably not have detected a large proportion of the local variations. This might explain the poor result of the global OLS model.

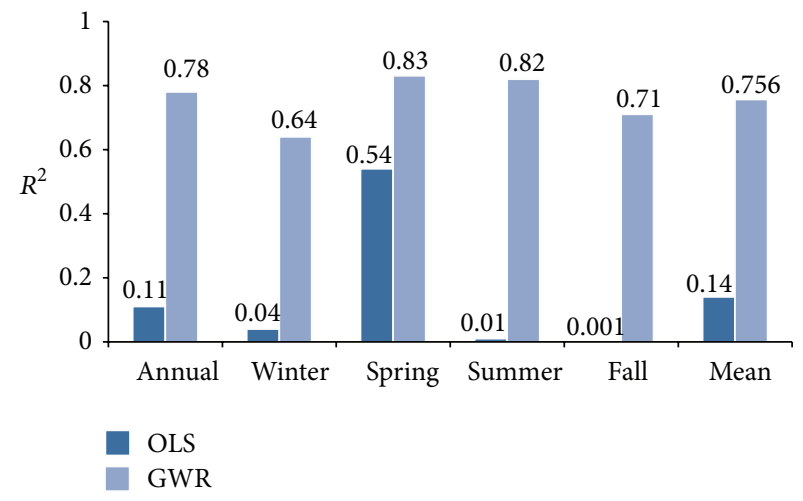

FIgURE 7: Coefficient of determination $\left(r^{2}\right)$ derived by OLS and GWR models.

Generally, as shown in Table 2, the GWR model replicated and fitted the data reasonably well, as the altitude explained $78 \%$ of the spatial variation of the annual rainfall $\left(r^{2}=\right.$ 0.78) in Saudi Arabia. As for seasonal rainfall, the most predictable seasonal rainfall was in spring $\left(r^{2}=0.83\right)$ and in summer $\left(r^{2}=0.82\right)$, which implied a very strong spatial correlation between altitude and rainfall during these two seasons. Fall $\left(r^{2}=0.71\right)$ and winter $\left(r^{2}=0.64\right)$ results accounted for the least but still indicated strong correlations. GWR models built a local regression equation for each rainfall station in the study area. However, when the values for the altitude variable cluster spatially, there are likely to be problems with local collinearity. Results become unstable and the model becomes unreliable in the presence of local collinearity, which is tested using condition number (CN) and Moran's I. As can be seen from Table 2, all CN numbers are less than 30, indicating that no local collinearity is violated. Another appropriate test statistic is Moran's I, which is used to measure the level of spatial autocorrelation in the residuals. Given that the $z$-score was less than -1.65 or greater than 1.65 for annual and seasonal rainfalls, indicating that the pattern of the standardized residual did not appear to be statistically different than random, there is no spatial dependency. The residuals were approximately normal and fewer than $2.5 \%$ (5/180) of the rainfall stations which had standardized residuals greater than 3 standard deviations above or below the mean (Table 2). However, the rainfall stations with these extreme residuals were scattered throughout Saudi Arabia and were not clustered in a particular area. 


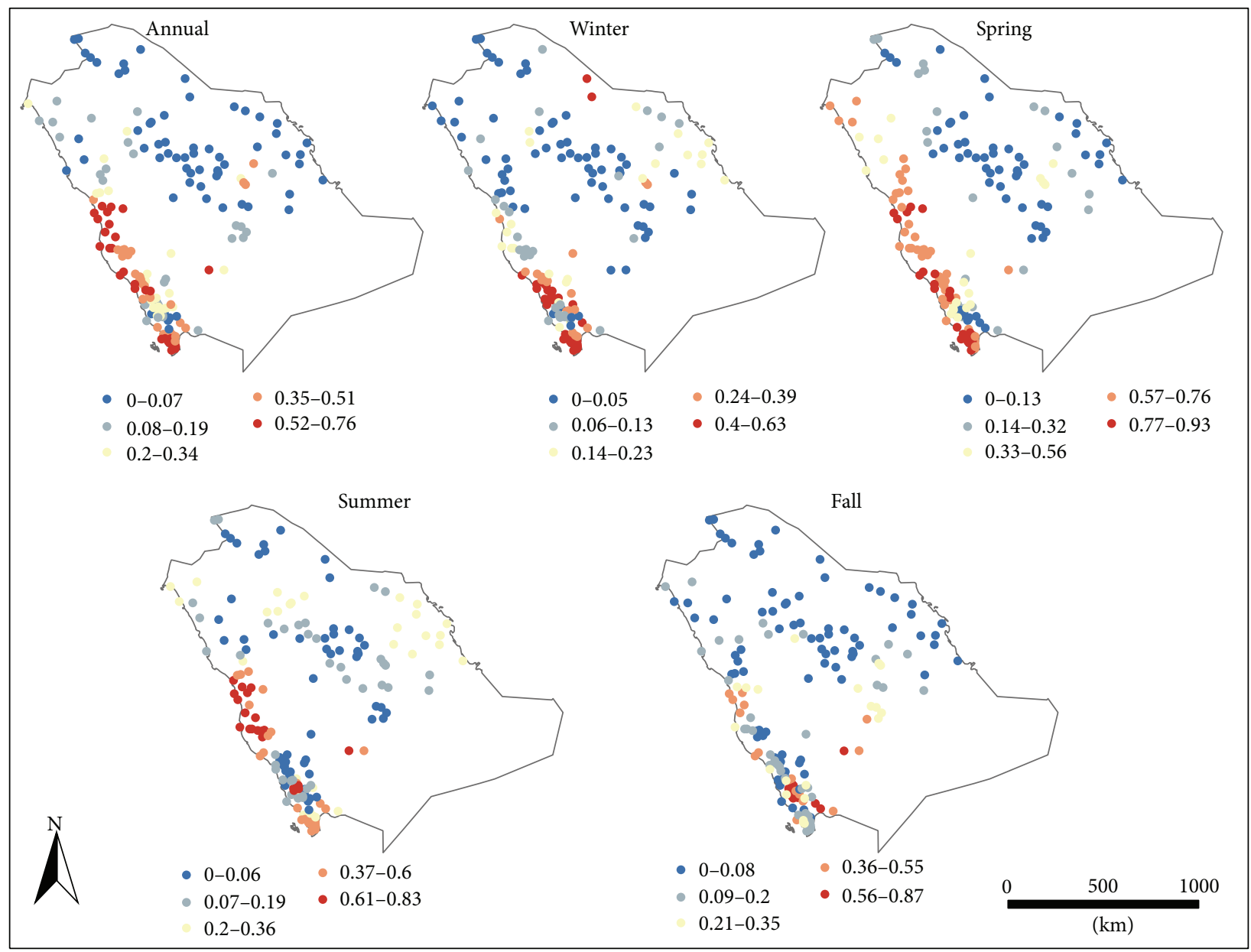

FIGURE 8: Locally weighted coefficients of determination $\left(r^{2}\right)$ of GWR models for annual and seasonal rainfalls.

The authors deduced from this that the GWR models fitted the data reasonably with no local collinearity and spatial dependency.

The locally weighted coefficients of determination $\left(r^{2}\right)$ that quantify the model performance between the observed and fitted rainfall values were mapped in Figure 8 for annual and seasonal rainfalls. The values of $r^{2}$ were not homogenously distributed in Saudi Arabia. The overall GWR regression fitted best in the southwest and central west of the Kingdom for annual and spring rainfall; in the southwest during winter; in the central west during summer, and in small parts of the southwest region during fall. The authors deduced from this that the model performed well and took account of the spatial variations in rainfall in the complex physiographic terrain of the Arabian Shield (western half of Saudi Arabia), which included the Hijaz and Asir escarpments, the western and eastern slopes of the escarpments, foothills, and the Tihama (coastal plain). Although the amounts of average annual rainfall varied spatially in this complex topography, the model took account of this variation reasonably well.

The GWR model also fitted the east and northeast during winter and summer. As for winter, the result produced a moderate fitting of an inverse relationship (high rainfall in low altitude), as rainfall in this season is mainly due to the effect of the Mediterranean Sea depressions. In summer, the results produced a moderate fitting of a weak positive relationship (low rainfall in low altitude), as average annual rainfall during this season is low. The model did not produce results that correspond well in the central, northern, and northeastern regions for annual and all seasons' rainfall in the eastern region for annual, spring and fall rainfall; and in the southwest during summer and fall. The authors deduced from this that much of the variance remained unexplained in those areas and other variables would have to be included in the model specification, such as proximity to moisture source, air mass movements, temperature, and pressure.

The spatial variation of the GWR parameter estimation for altitude is shown in Figure 9. Where the altitude parameter estimation values are large, the authors deduced that a small increase in altitude corresponds to a large increase in rainfall amount. During annual and seasonal rainfalls, the relationship between rainfall and altitude showed that increased rainfalls would be strongly related to increased altitude in the southern and southwestern area of the Red Sea. The reason for this can be attributed to the local topography and air mass movement. According to Figures 2 and 3, it can 


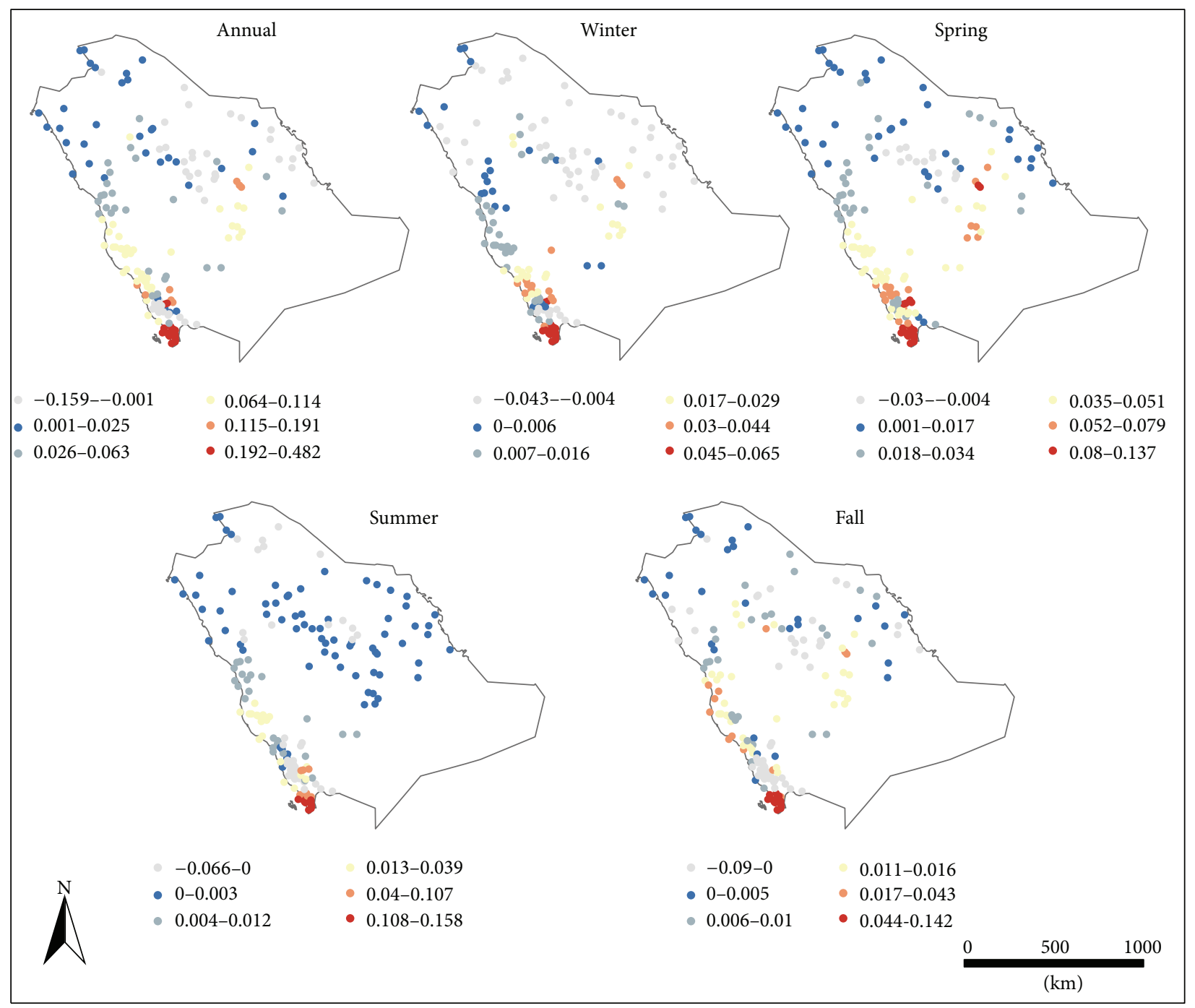

FIGURE 9: GWR parameter estimation of the altitude for annual and seasonal rainfalls.

be noted that the escarpment ridge of the Asir Mountains is divided in the southwestern region into two distinct zones, namely, the western and the eastern slopes. The latter are characterized by gentle slopes but the former by very steep slopes.

The authors felt that this implies that the altitude on the western slopes decreased rapidly; forming the western foothills, while on the eastern slopes, altitude decreased more gradually, forming the plateau. The western slopes received more rainfall than did the eastern slopes, as the former were located on the windward side while the latter were on the leeward side. As the western slopes are in close proximity to the water bodies of the Red Sea, and the coastal area is located in close proximity to the foothills of the western slopes, topographic and climatic influences promote the uplifting mechanisms of the moist air to the Asir highlands.

The central western coast and the area along the Tuwayq Mountains showed a moderate positive relationship between altitude and rainfall during annual as well as seasonal rainfalls. The relationship between rainfall and altitude is quite limited in the northern half of Saudi Arabia. Higher altitude areas do not necessarily receive more rainfall, but some locations with high altitude receive low rainfall (inverse relationship), such as the eastern slopes in the southwest region particularly during summer and fall. This can be attributed to the monsoon front during late fall and summer that originates from the Indian Ocean and Arabian Sea, carrying warm and moist air. Additionally, inverse relationship between altitude and rainfall can be apparent in the central, east, and northeast areas of Saudi Arabia during winter. In the eastern area at low altitudes (eastern coast), high rainfall occurs in winter, while in the central and the northeast areas at moderate altitude, there is low rainfall.

The spatial variation of the GWR parameter estimation of the intercept is shown in Figure 10. The map of the intercept represents the distribution of rainfall when altitude equals zero, that is, where the intercept values are large, which reveals that rainfall amounts are high irrespective of the 


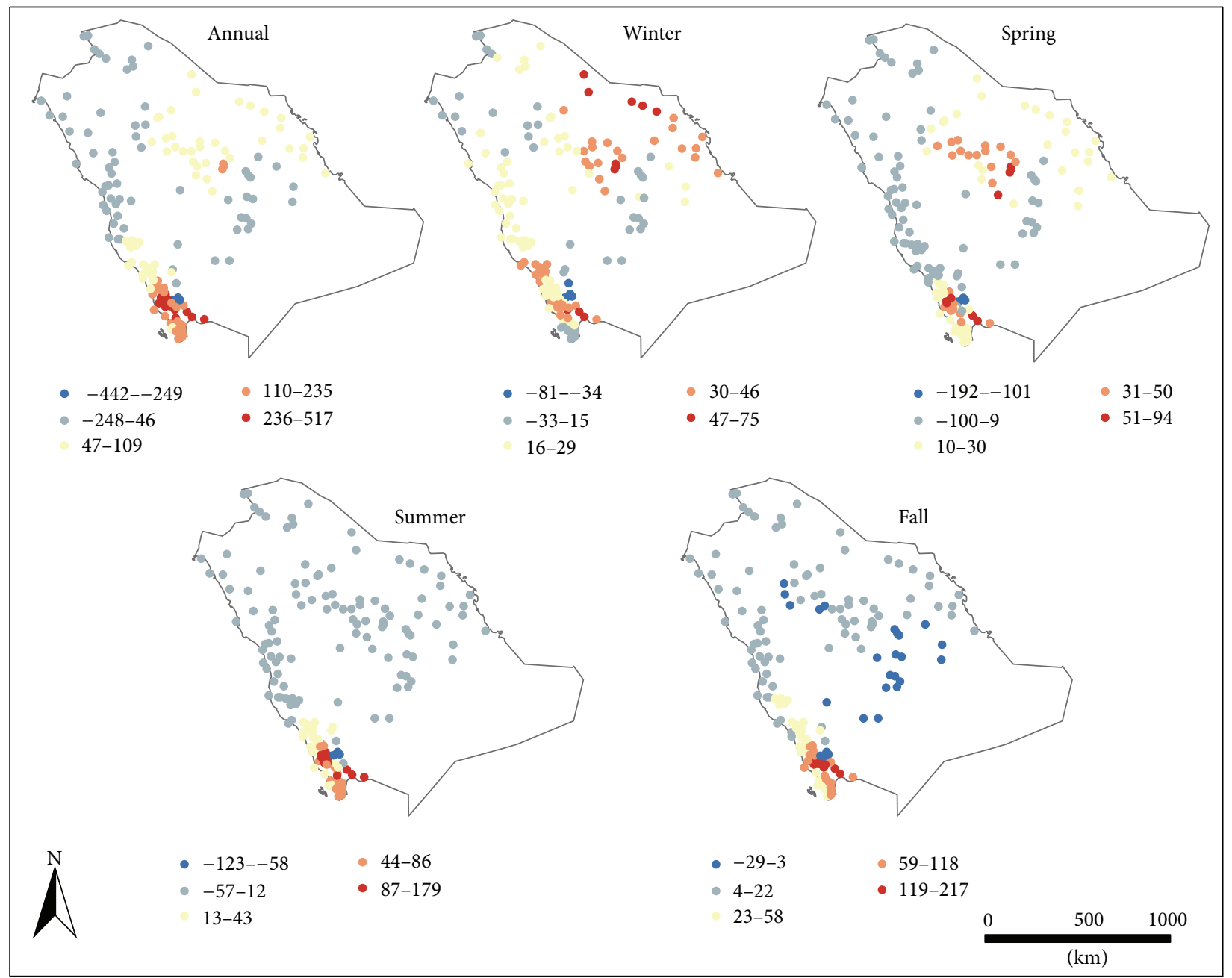

FIGURE 10: GWR parameter estimation of the intercept for annual and seasonal rainfalls.

TABLE 3: Observed versus estimated mean amount of annual and seasonal rainfalls (1971-2005) using GWR.

\begin{tabular}{lccccccccc}
\hline \multirow{2}{*}{ Season } & \multicolumn{3}{c}{ Observed } & \multicolumn{3}{c}{ Estimated } & \multicolumn{3}{c}{ Observed - Estimated } \\
& Min & Max & Stand. Dev. & Min & Max & Stand. Dev. & $\Delta$ Min & $\Delta$ Max & $\Delta$ Stand. Dev. \\
\hline Annual & 5 & 592 & 104 & 20 & 464 & 84 & 15 & 128 & 20 \\
Winter & 2 & 113 & 20 & 6 & 81 & 13 & 4 & 32 & 7 \\
Spring & 1 & 180 & 38 & 2 & 158 & 33 & 1 & 22 & 5 \\
Summer & 0 & 208 & 36 & 1 & 159 & 31 & 1 & 49 & 5 \\
Fall & 0 & 211 & 34 & 1 & 102 & 26 & 1 & 109 \\
\hline
\end{tabular}

altitude. In general, it can be seen that intercept values tend to be positive and large in parts of the southwestern region for annual and seasonal rainfall. Additionally, positive and large intercept values occurred in the central, east, and northeast regions during winter and in the central areas during spring, while during summer and fall, large values occurred only in the southwest region. The interpretation of the altitude parameter estimation supports the assumption that the areas at lower elevations might receive high rainfall while those at higher elevations might receive low rainfall due to the local topography as a result of proximity to sources of moist air and seasonal air mass movements.
Table 3 shows the descriptive statistics of the observed versus the estimated mean amounts of rainfall in addition to the spatial and temporal variation of the estimated amount of rainfall in Figure 11. Note that the overall spatiotemporal variation and the pattern of rainfall distribution are estimated reasonably well compared to the observed pattern. However, there is variation in the maximum and minimum amounts of rainfall. The minimum mean amounts of rainfall are overestimated (small range), while the maximum mean amounts were underestimated (large range) for both annual and seasonal rainfalls. The differences between the observed and the estimated minimum amounts of mean rainfall 


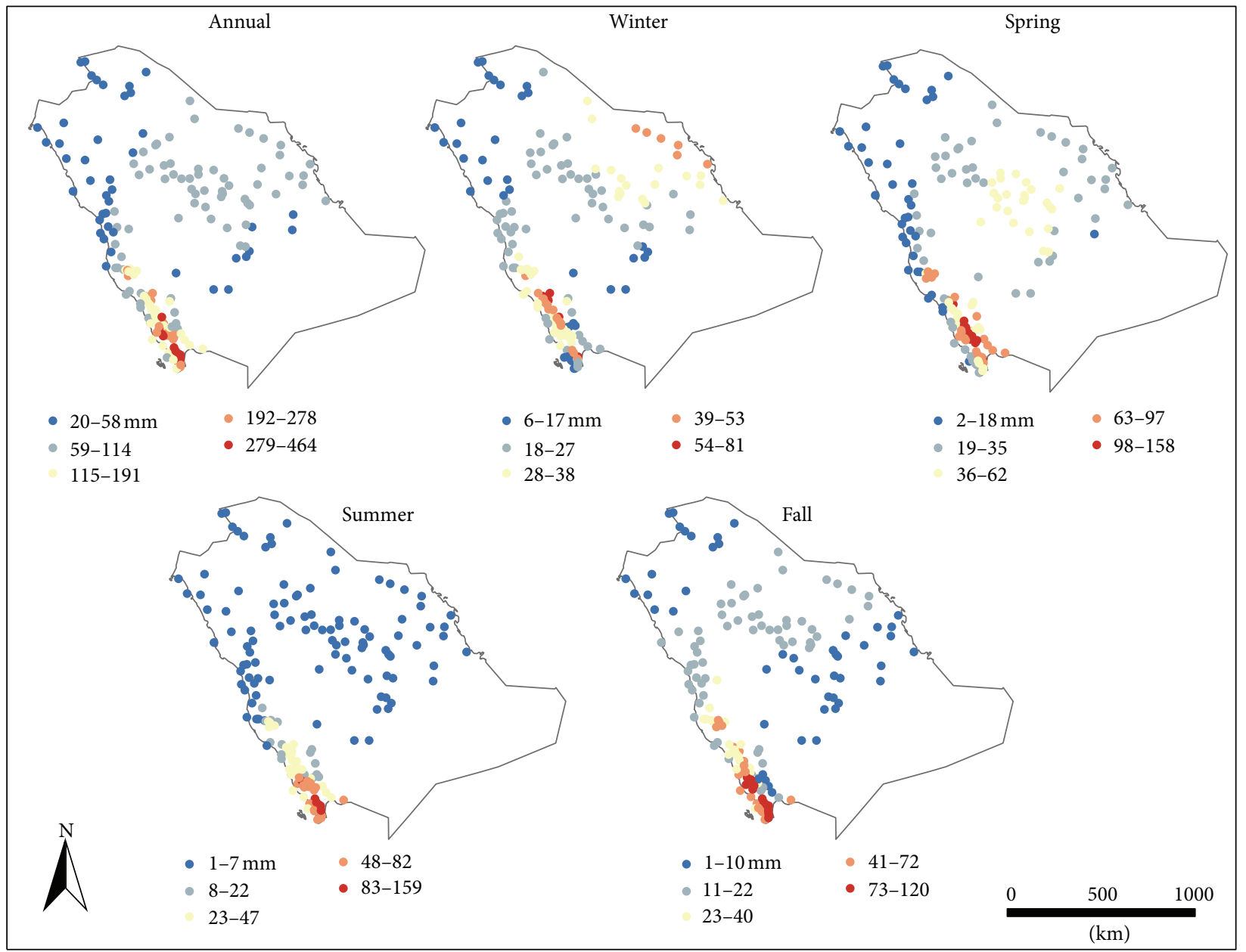

FIGURE 11: Estimation of mean annual and seasonal rainfalls in Saudi Arabia (1971-2005) using GWR.

( $\Delta$ Min) are small, ranging between 1 and $4 \mathrm{~mm}$ for seasonal rainfalls and $15 \mathrm{~mm}$ for annual rainfall. The largest differences between the maximum observed and predicted mean rainfall $(\triangle \mathrm{Max})$ are for annual $(128 \mathrm{~mm})$ and fall $(102 \mathrm{~mm})$, followed by summer $(49 \mathrm{~mm})$. Winter and spring show the lowest differences with $32 \mathrm{~mm}$ and $22 \mathrm{~mm}$, respectively. As for the large underestimation of the maximum values ( $\triangle \mathrm{Max})$, this is not surprising, since the peak value of the observed maximum mean rainfalls is extreme and represents one or two rainfall stations among the 180 stations during summer and fall and the difference would be lower without the extreme stations. The lowest maximum difference $(\Delta \mathrm{Max})$ during spring suggests that spring rainfalls are predicted well for both the spatiotemporal pattern and average annual rainfall.

\section{Conclusions}

In this research, the relationships between rainfall and altitude of the terrain in Saudi Arabia were analyzed using the global ordinary least square (OLS) and the local geographically weighted regression (GWR) methods using a geographical information system. The monthly rainfall data between 1971 and 2005 for 180 rainfall stations were modeled using these methods and the results were compared and critically evaluated. The smoothed altitude values for rainfall stations were reported as producing results that gave a better account of the results than did using the absolute altitude at the rainfall station sites. In this study, different smoothing window sizes were used and assessed and the $15 \mathrm{~km}$ window size was selected because it produced the highest value of the coefficient of determination and showed improvements in the resulting regression equations.

One the one hand, the OLS results could account for about $54 \%$ of the variation for spring rainfall, while the results were unsatisfactory for the annual and other seasonal data only accounting for less than $11 \%$ of the variation. On the other hand, the GWR could account much better for the spatial variation of the annual and seasonal rainfall with results of $64 \%$ to $83 \%$. Analyses showed that the positive association between rainfall and altitude was most pronounced in the south-west part along the escarpment ridge of the Asir Mountains, in the west part along the Hijaz Escarpment and through a moderate relationship along the Tuwayq Mountains. The model was not such a good fit in 
the central, northern, and north-eastern areas because much of the variance remained unexplained in those areas and other variables would have to be introduced into the model to obtain improved results. The results showed that higher altitudes do not always receive more rainfall; some locations with low altitude receive more rainfall such as the eastern and north-eastern parts during winter where the rainfall is chiefly due to the effect of the passage of depressions emanating from the Mediterranean Sea.

The physical characterizations of the altitude variable used in the GWR models produced regression equations that returned satisfactory values of the coefficient of determination with random standardized residuals. The local regression equations could be fitted to other periods in Saudi Arabia to estimate the mean annual and seasonal rainfalls. Moreover, the altitude variables used in this study can be derived automatically from digital elevation model data which is free and available online. As the GWR derived a local regression equation for each rainfall station, one can use the altitude as a covariate variable in spatial interpolation for producing rainfall maps, particularly for those stations and areas with high coefficients of determination. The authors concluded that using a nonstationary local model such as GWR gave a much better account than using a global model such as OLS in terms of spatial estimation and prediction. It was also concluded that the results could have significant implications for rainfall-runoff studies in the country. Further research on this topic in Saudi Arabia should therefore focus on including more independent variables such as proximity to moisture source, air mass movements and wind direction, temperature, and pressure.

\section{Conflict of Interests}

The authors declare that they have no conflicts, relevant or material financial interests that relate to the research described or trademarks mentioned in this paper.

\section{References}

[1] M. A. Abdullah and M. A. Al-Mazroui, "Climatological study of the southwestern region of Saudi Arabia-I. Rainfall analysis," Climate Research, vol. 9, no. 3, pp. 213-223, 1998.

[2] A. M. Subyani, "Topographic and seasonal influences on precipitation variability in southwest Saudi Arabia," Journal of King Abdulaziz University, vol. 11, pp. 89-102, 1999.

[3] M. Gouvas, N. Sakellariou, and F. Xystrakis, "The relationship between altitude of meteorological stations and average monthly and annual precipitation," Studia Geophysica et Geodaetica, vol. 53, no. 4, pp. 557-570, 2009.

[4] M. S. Alyamani and Z. Sen, "Regional variations of monthly rainfall amounts in the Kingdom of Saudi Arabia," Journal of King Abdulaziz University, vol. 6, pp. 113-133, 1993.

[5] A. Basist and G. D. Bell, "Statistical relationships between topography and precipitation patterns," Journal of Climate, vol. 7, pp. 1305-1315, 1994.

[6] D. Hayward and R. T. Clarke, "Relationship between rainfall, altitude and distance from the sea in the Freetown Peninsula,
Sierra Leone," Hydrological Sciences Journal, vol. 41, no. 3, pp. 377-384, 1996.

[7] C. E. Konrad, "Relationships between precipitation event types and topography in the southern blue ridge mountains of the southeastern USA," International Journal of Climatology, vol. 16, no. 1, pp. 49-62, 1996.

[8] B. Sevruk, K. Matokova-Sadlonova, and L. Toskano, “Topography effects on small-scale precipitation variability in the Swiss pre-Alps," IAHS-AISH Publication, vol. 248, pp. 51-58, 1998.

[9] P. Oettli and P. Camberlin, "Influence of topography on monthly rainfall distribution over East Africa," Climate Research, vol. 28, no. 3, pp. 199-212, 2005.

[10] W. Buytaert, R. Celleri, P. Willems, B. D. Bièvre, and G. Wyseure, "Spatial and temporal rainfall variability in mountainous areas: a case study from the south Ecuadorian Andes," Journal of Hydrology, vol. 329, no. 3-4, pp. 413-421, 2006.

[11] B. Alijani, "Effect of the Zagros Mountains on the spatial distribution of precipitation," Journal of Mountain Science, vol. 5, no. 3, pp. 218-231, 2008.

[12] K. Al-Ahmadi, S. Al-Ahmadi, and L. See, "Spatio-temporal variations in rainfall-topographic features relationships in the Southwest Region of Saudi Arabia," Arabian Journal of Geosciences. In press.

[13] M. J. Abdulrazzak, A. U. Sorman, H. Onder, and A. M. Al-Sari, "Flood estimation and impact: southwestern region of Saudi Arabia," Final report AR-10-51, KACST, Riyadh, Saudi Arabia, 1995.

[14] N. Hatzianastassiou, B. Katsoulis, J. Pnevmatikos, and V. Antakis, "Spatial and temporal variation of precipitation in Greece and surrounding regions based on Global Precipitation Climatology Project data," Journal of Climate, vol. 21, no. 6, pp. 1349-1370, 2008.

[15] V. P. Schermerhorn, "Relations between topography and annual precipitation in western Oregon and Washington," Water Resources Research, vol. 3, pp. 707-711, 1967.

[16] B. Raab and H. Vedin, Eds., Sweden'S National Atlas: Climate, Lakes and Waters, Bokforlaget Bra Bocker, 1995.

[17] G. L. Johnson and C. L. Hanson, "Topographic and atmospheric influences on precipitation variability over a mountainous watershed," Journal of Applied Meteorology, vol. 34, no. 1, pp. 6887, 1995.

[18] C. Prudhomme and D. W. Reed, "Relationships between extreme daily precipitation and topography in a mountainous region," International Journal of Climatology, vol. 18, pp. 1439$1453,1998$.

[19] C. Prudhomme and D. W. Reed, "Mapping extreme rainfall in a mountainous region using geostatistical techniques," International Journal of Climatology, vol. 19, pp. 1337-1356, 1999.

[20] P. C. Kyriakidis, J. Kim, and N. L. Miller, "Geostatistical mapping of precipitation from rain gauge data using atmospheric and terrain characteristics," Journal of Applied Meteorology, vol. 40, no. 11, pp. 1855-1877, 2001.

[21] G. Drogue, J. Humbert, J. Deraisme, N. Mahr, and N. Freslon, "A statistical-topographic model using an omnidirectional parameterization of the relief for mapping orographic rainfall," International Journal of Climatology, vol. 22, no. 5, pp. 599-613, 2002.

[22] S. Naoum and I. K. Tsanis, "A multiple linear regression GIS module using spatial variables to model orographic rainfall," Journal of Hydroinformatics, vol. 6, pp. 39-56, 2004. 
[23] S. Naoum and I. K. Tsanis, "Orographic precipitation modeling with multiple linear regression," Journal of Hydrologic Engineering, vol. 9, no. 2, pp. 79-102, 2004.

[24] G. K. Chaun and J. G. Lockwood, "An assessment of topographical controls on the distribution of rainfall in the central Pennines," Meteorological Magazine, vol. 103, pp. 275-287, 1974.

[25] F. F. Hill, K. A. Browning, and M. J. Bader, "Radar and raingauge observations of orographic rain over south Wales," Quarterly Journal, Royal Meteorological Society, vol. 107, no. 453, pp. 643670, 1981.

[26] D. E. Pedgley, "Heavy rainfalls over Snowdonia," Weather, vol. 25, pp. 340-350, 1970.

[27] B. Johansson and D. Chen, "The influence of wind and topography on precipitation distribution in Sweden: statistical analysis and modelling," International Journal of Climatology, vol. 23, no. 12, pp. 1523-1535, 2003.

[28] M. Gouvas and N. Sakellariou, "Relation of the altitude of the meteorological stations to the average annual and monthly rainfall amount," in Proceedings of 7th Pan-Hellenic International Conference of Meteorology, Climatology and Atmospheric Physics, pp. 765-771, Nicosia, Cyprus, 2004.

[29] A. Páez, "Anisotropic variance functions in geographically weighted regression models," Geographical Analysis, vol. 36, no. 4, pp. 299-314, 2004.

[30] A. Getis and J. K. Ord, "The analysis of spatial association by use of distance statistics," Geographical Analysis, vol. 24, pp. 189206, 1992.

[31] A. S. Fotheringham, C. Brunsdon, and M. Charlton, Geographically Weighted Regression: the Analysis of Spatially Varying Relationships, Wiley, Chichester, UK, 2002.

[32] J. Mennis, "Mapping the results of geographically weighted regression," Cartographic Journal, vol. 43, no. 2, pp. 171-179, 2006.

[33] C. Brunsdon, J. McClatchey, and D. Unwin, "Spatial variations in the average rainfall-altitude relationships in Great Britain: an approach using geographically weighted regression," International Journal of Climatology, vol. 21, pp. 455-466, 2001.

[34] C. D. Lloyd, "Nonstationary models for exploring and mapping monthly precipitation in the United kingdom," International Journal of Climatology, vol. 30, no. 3, pp. 390-405, 2010.

[35] WASA, Water Atlas of Saudi Arabia, Ministry of Agriculture and Water, Riyadh, Saudi Arabia, 1988.

[36] ASTER GDEM, "ASTER Global Digital Elevation Model (ASTER GDEM)," 2010, http://www.jspacesystems.or.jp/ersdac/ GDEM/E/.

[37] M. Charlton and A. S. Fotheringham, Geographically Weighted Regression, National Centre For Geocomputation, National University of Ireland Maynooth, Maynooth, CoKildare, Ireland, 20092009.

[38] A. S. Fotheringham, M. E. Charlton, and C. Brundsdon, "Geographically weighted regression: a natural evolution of the expansion method for spatial data analysis," Environment and Planning A, vol. 30, no. 11, pp. 1905-1927, 1998.

[39] A. S. Fotheringham, C. Bunsden, and M. Charlton, Quantitative Geography, Sage, London, 2000.

[40] C. M. Hurvich, J. S. Simonoff, and C. L. Tsai, "Smoothing parameter selection in nonparametric regression using an improved Akaike information criterion," Journal of the Royal Statistical Society Series B, vol. 60, no. 2, pp. 271-293, 1998.

[41] D. C. Wheeler, "Diagnostic tools and a remedial method for collinearity in geographically weighted regression," Environment and Planning A, vol. 39, no. 10, pp. 2464-2481, 2007.
[42] C. Brunsdon, M. Charlton, and P. Harris, "Living with collinearity in local regression models," in Proceedings of the 10th International Symposium on Spatial Accuracy Assessment in Natural Resources and Environmental Sciences, FlorianópolisSC, Brazil, 2012.

[43] D. Belsey, E. Kuh, and R. Welsch, Regression Diagnostics: Identifying Influential Data and Sources of Collinearity, Wiley, Hoboken, NJ, USA, 2004.

[44] L. M. Scott and M. V. Janikas, "Spatial statistics in ArcGIS," in Handbook of Applied Spatial Analysis: Software, Tools, Methods and Application, M. M. Fischer and A. Getis, Eds., Springer, 2010.

[45] A. Mitchell, The ESRI Guide to GIS Analysis, Spatial Measurements and Statistics, ESRI, Redlands, Calif, USA, 2005.

[46] M. C. Peel, B. L. Finlayson, and T. A. McMahon, "Updated world map of the Köppen-Geiger climate classification," Hydrology and Earth System Sciences Discussions, vol. 4, no. 2, pp. 439-473, 2007.

[47] B. Y. M. Ahmed, "Climatic classification of Saudi Arabia: an application of factor cluster analysis," Geo Journal, vol. 41, pp. 69-84, 1997.

[48] Z. Sen, "Hydrology of Saudi Arabia," in Proceedings of the Symposium on Water Resources in Saudi Arabia, pp. A68-A94, Scientific Publishing Centre, King Saud University, Riyadh, Saudi Arabia, 1983.

[49] M. S. Alyamani, "Isotopic composition of rainfall and groundwater recharge in the western province of Saudi Arabia," Journal of Arid Environments, vol. 49, no. 4, pp. 751-760, 2001.

[50] MacLaren International Limited, "Water and agricultural development studies-Arabian Shield-South," in Hydrogeological Investigations, Annex 3, Ministry of Agriculture and Water, Riyadh, Saudi Arabia, 1979.

[51] M. D. Al-Qurashi, Synoptic climatology of the rainfall in the southwest region of Saudi Arabia [Master Dissertation], Department of Geography, University of Western Michigan, 1981.

[52] Z. Şen and K. Al-Suba'i, "Hydrological considerations for dam siting in arid regions: a Saudi Arabian study," Hydrological Sciences Journal, vol. 47, no. 2, pp. 173-186, 2002.

[53] A. M. Subyani, A. A. Al-Modayan, and F. S. Al-Ahmadi, "Topographic, seasonal and aridity influences on rainfall variability in western Saudi Arabia," Journal of Environmental Hydrology, vol. 18, pp. 1-11, 2010.

[54] K. P. Burnham and D. R. Anderson, Model Selection and Multimodel Inference: A Practical Information-Theoretical Approach, Springer, New York, NY, USA, 2nd edition, 2002.

[55] C. D. Lloyd, Local Models for Spatial Analysis, CRC Press, Boca Raton, Fla, USA, 2011.

[56] R. Mandal, S. St-Hilaire, J. G. Kie, and D. Derryberry, "Spatial trends of breast and prostate cancers in the United States between 2000 and 2005," International Journal of Health Geographics, vol. 8, no. 1, article 53, 2009.

[57] C. H. Lin and T. H. Wen, "Using geographically weighted regression (GWR) to explorespatial varying relationships of immature mosquitoes andhuman densities with the incidence of dengue," International Journal of Environmental Research and Public Health, vol. 8, no. 7, pp. 2798-2815, 2011. 

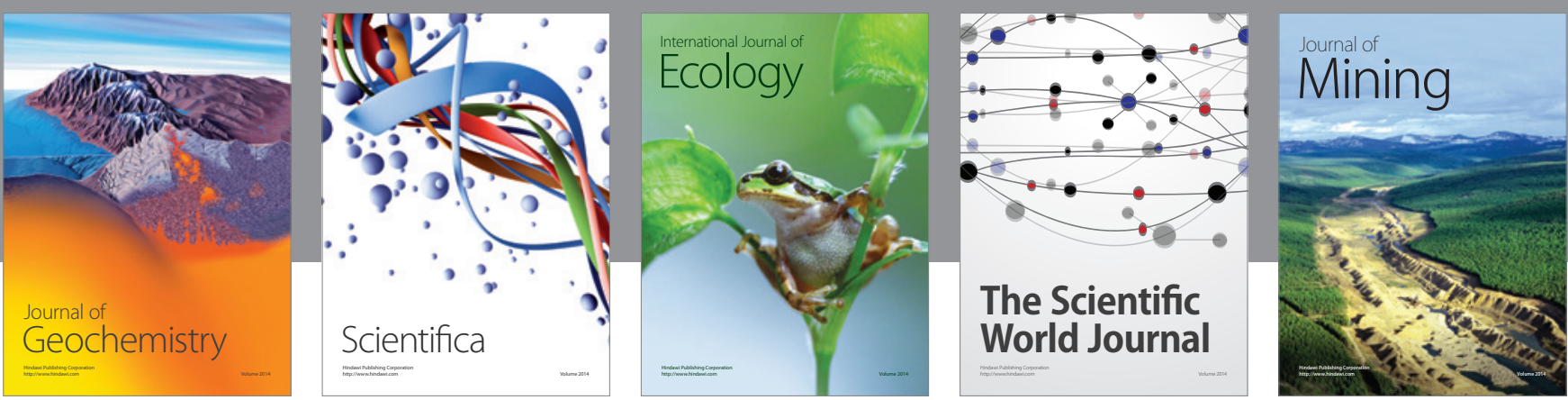

The Scientific World Journal
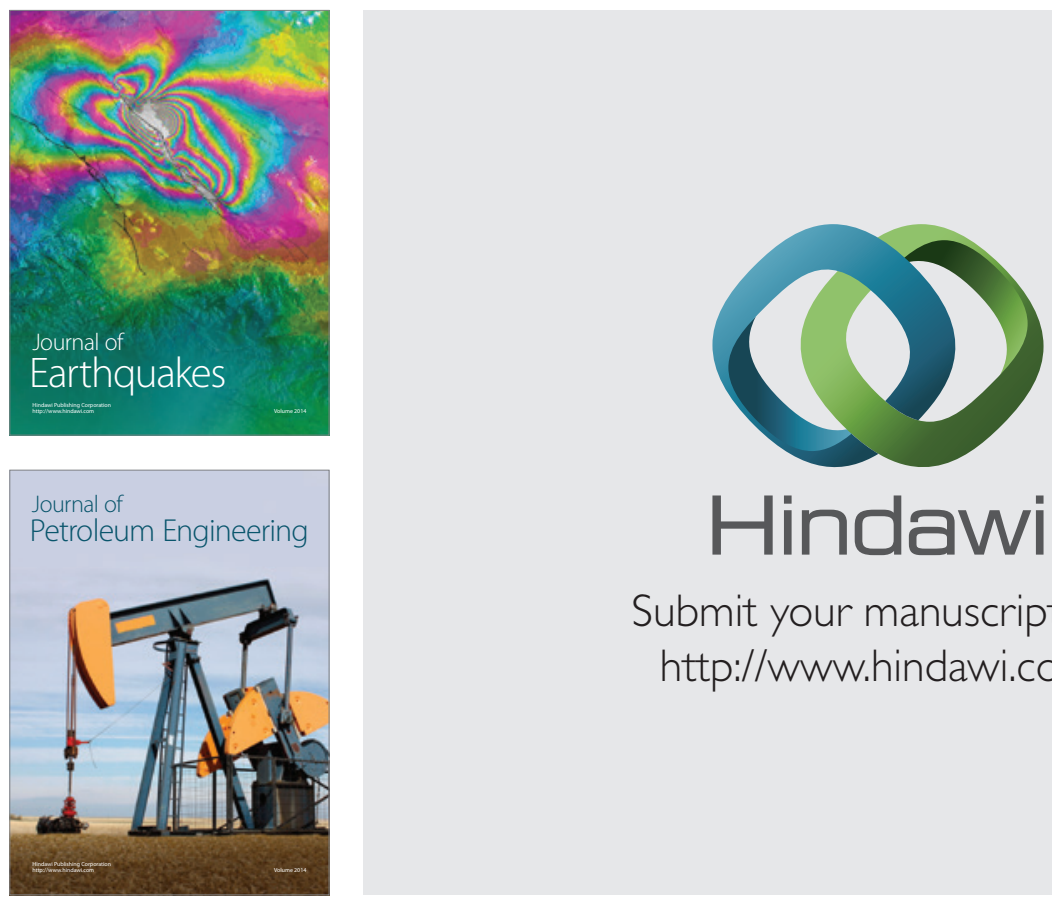

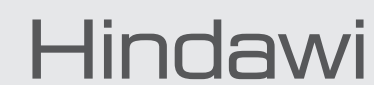

Submit your manuscripts at

http://www.hindawi.com
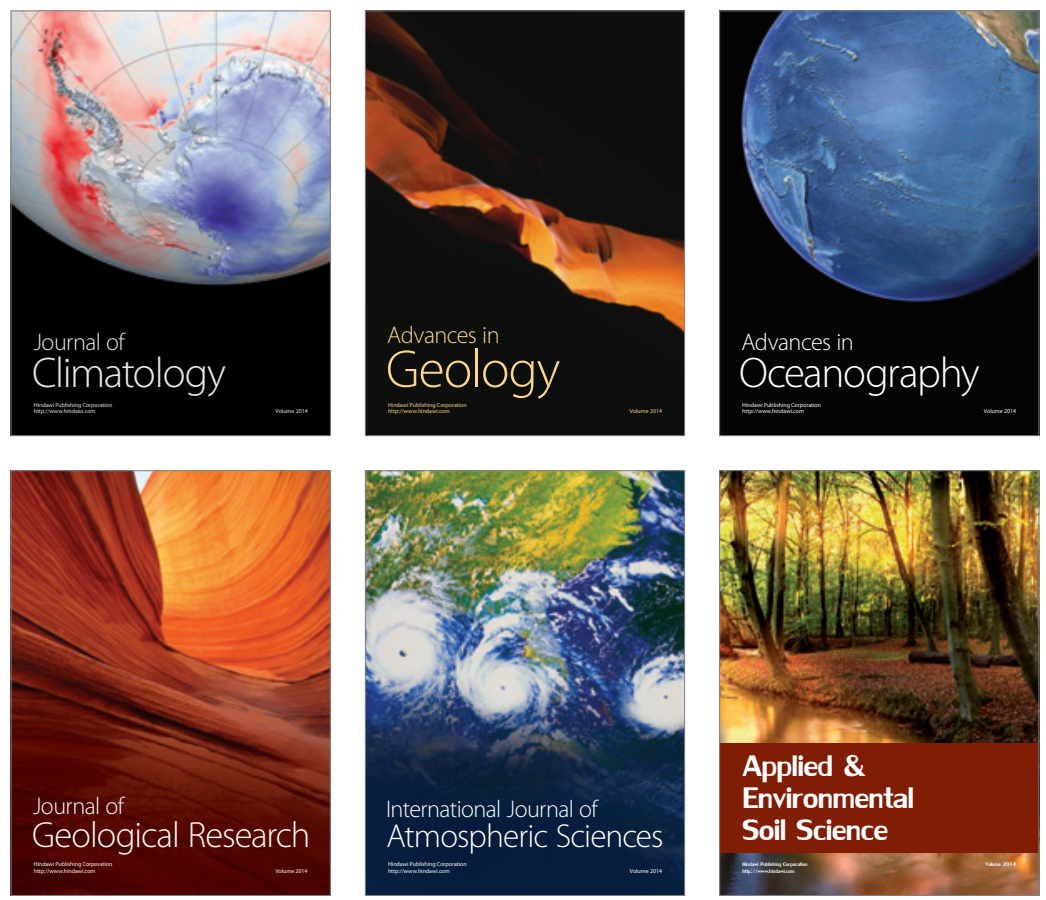
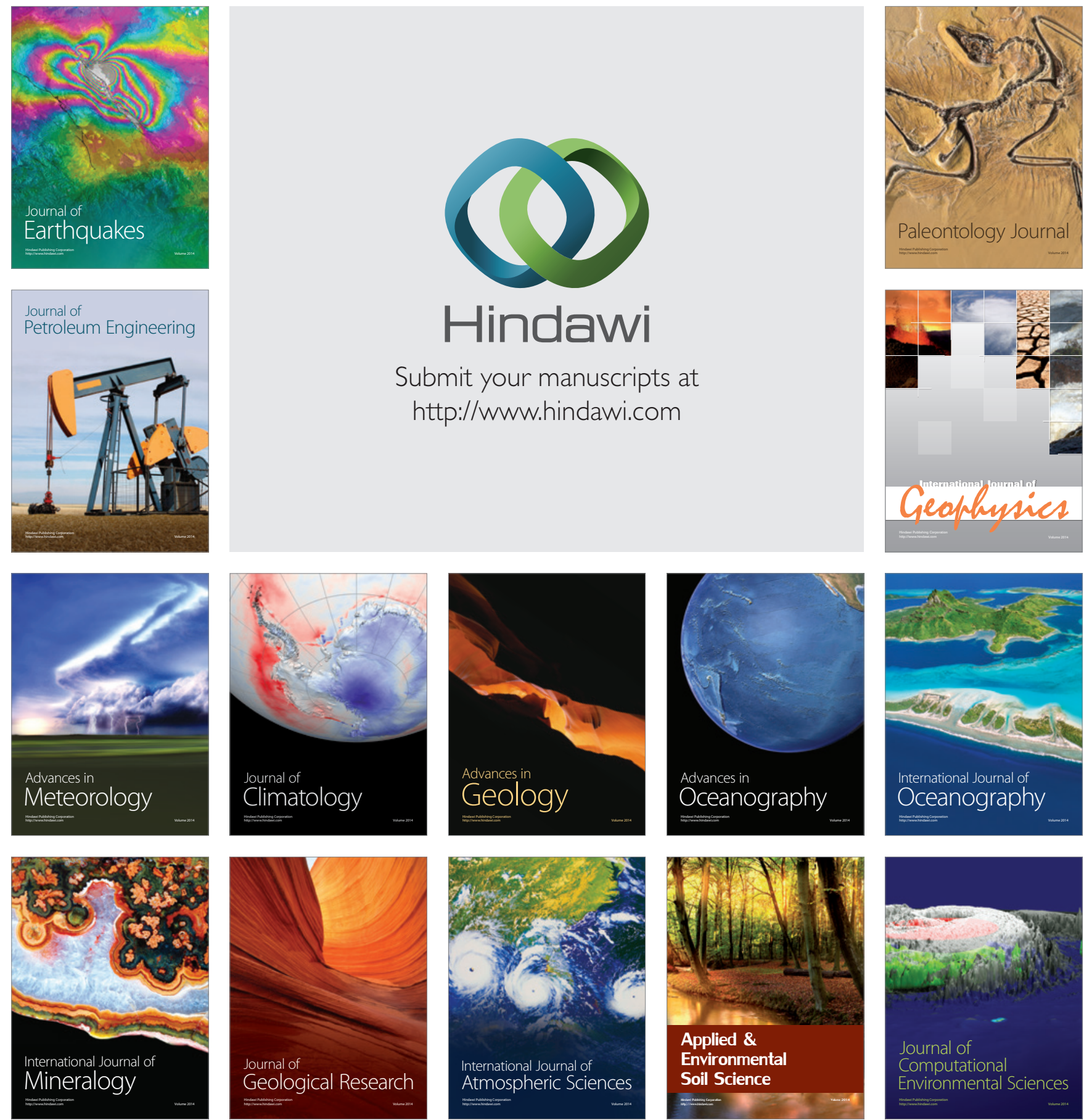